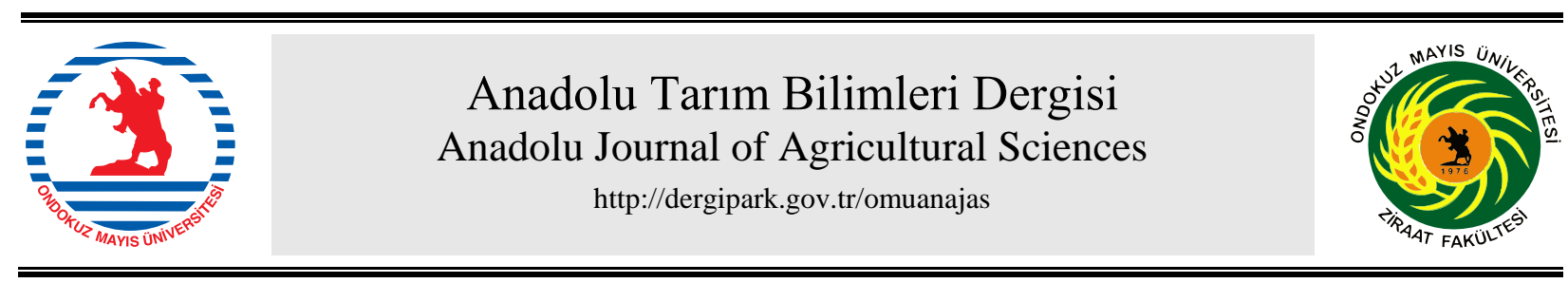

Araştırma/Research

Anadolu Tarım Bilim. Derg./Anadolu J Agr Sci, 33 (2018)

ISSN: 1308-8750 (Print) 1308-8769 (Online)

doi: 10.7161/omuanajas. 322340

\title{
Lilyum zambaklarında (lilium sp.) farklı yetiştirme ortamlarının yavru soğan oluşumu ve gelişimi üzerine etkisi
}

\author{
Leyla Eken ${ }^{\mathrm{a}}$, Uğur Şirin ${ }^{\mathrm{b}}$ \\ ${ }^{a}$ Aydın Adnan Menderes Üniversitesi, Çine Meslek Yüksekokulu, Çine, Aydın \\ ${ }^{b}$ Aydın Adnan Menderes Üniversitesi, Ziraat Fakültesi Bahçe Bitkileri Bölümü, Aydın \\ *Sorumlu yazar/corresponding author: leyla.saygili@adu.edu.tr
}

Geliş/Received 19/06/2017～Kabul/Accepted 01/02/2018

\begin{abstract}
ÖZET
Lilium sp. yetiştiriciliğinde soğan üretimi çoğunlukla toprakta yapılmakla birlikte, toprağın fiziksel ve kimyasal özellikleri, hastalık ve zararlılar nedeni ile üretimde sorunlar yaşanmaktadır. Bununla birlikte, toprak özellikleri bir lilyum soğanının çiçek oluşturacak iriliğe ulaşma süresini de olumsuz etkileyebilmektedir. Söz konusu sorunların çözümü amacı ile bu araştırmada toprağa alternatif farklı yetiştirme ortamlarının yavru soğan oluşumu ve gelişimi üzerine etkilerinin belirlenmesi amaçlanmıştır. Deneme 2011 yılı ilkbahar döneminde yürütülmüş ve Lilium LA hybrids "Ceb Dazzle" çeşidi kullanılmıştır. Çalışmada;(1) kestane kabuğu + perlit, (2) yerfıstığı kabuğu + perlit, (3) kum + yerfistığı kabuğu, (4) perlit, (5) kestane kabuğu+kum, (6) bahçe toprağı+ahır gübresi+torf (kontrol), (7) torf+kum, (8) hindistan cevizi kabuğu, (9) volkanik curuf olmak üzere farklı yetiştirme ortamları deneme konularını oluşturmuştur. Lilyum bitkileri $60 \mathrm{~L}$ hacimli plastik kasalar içerisine doldurulan yetiştirme ortamlarında yetiştirilmiştir. Denemede soğan gelişme özelliklerinin belirlenmesi amacıyla ana soğanda ve bitki gövdesi üzerinde oluşan köklerin özellikleri incelenmiş, yavru soğan oluşumu ve gelişimine ilişkin özelliklerin belirlenmesi amacıyla ise ana soğanda ve bitki gövdesi üzerinde gelişen yavru soğan sayısı, ağırlı̆̆ı, en ve boy değerleri belirlenmiştir. Araştırma sonucunda; ana soğanlar üzerinde yavru soğan oluşumu görülmezken gövde üzerinde yavru soğan oluşumu gözlenmiş ve incelenmiştir. En fazla yavru soğan oluşumu 17.5 adet/soğan ile yer fistı̆̆ kabuğu+kum yetiştirme ortamında yetiştirilen soğanlarda elde edilmiştir. Yavru soğan ortalama ağırlığı, en ve boy değerleri açısından en iyi gelişimlerin yerfistığı kabuğu+kum $(12.387 \mathrm{~g}, 14.34 \mathrm{~mm}$ en, $14.54 \mathrm{~mm}$ boy) ve torf+kum ( $8.983 \mathrm{~g}, 13.31 \mathrm{~mm}$ en ve $14.42 \mathrm{~mm}$ boy) yetiștirme ortamından elde edildiği belirlenmiștir.
\end{abstract}

Effects of different substrates on formation and development of bulblets in Lilium sp.

\section{ABSTRACT}

Although lilium sp. bulb growth has been mostly performed in soil, there are problems in production of bulbs because of physical and chemical properties of soil, diseases and pests. Properties of soil also effects time of formation of suitable bulb size to form flowers in lilium bulb. In this study it was aimed to determine the effects of different alternative substrates on bulblet formation and development to sole the probles on propagation of new bulblets in Lilium.Study was performed in spring, 2011 and Lilium LA hybrids cv. "Ceb Dazzle" was used. In this study, (1) chestnut shell + perlite, (2)peanut shell + perlite, (3)sand + peanut shell, (4) perlit, (5) chestnut shell + sand, (6) soil + organic manure + peat (control), (7) peat + sand, (8) cocopeat, (9) volcanic tuff were used as substrates. Lilium plants were grown in $60 \mathrm{~L}$ volumed plastic boxes filled with substrates. In order to determine the properties of bulb development, roots which are formed on bulbs and stems were analyzed. And in order to determine the formation and development of bulblets, bulblets formed in mother bulb and plant stem were analyzed in terms of number of bulbs, weight, length and height.As a result of this research, instead of there weren't any bulblet formation on the mother bulbs, it was observed that there is bulblet formation on plant stems and they were analized. The highest number of bulblet formation was obtained in Sand+Peanut Shell substrat mix with the 17.5 number/bulb. It is determined that, the best results in terms of average weight, lenght and height diameter of bulblets, were obtained on Sand+Peanut Shell (12.387 g,14.34 mm lenght, $14.54 \mathrm{~mm}$ height) and Peat+Sand ( $8.983 \mathrm{~g}, 13.31 \mathrm{~mm}$ lenght ve $14.42 \mathrm{~mm}$ height) substrats.

Anahtar Sözcükler: Lilyum Yavru soğan Yetiştirme ortamı Kestane kabuğu Yerfistığı kabuğu
Keywords: Lilium Bulblets Substrat Chestnut shell Chestnut shell

(C) OMU ANAJAS 2018 


\section{Giriş}

Kesme çiçek yetiştiriciliği, 2015 verilerine göre11.826.160 $\mathrm{m}^{2}$ üretim alanıyla hızlı büyüme ve gelişme gösteren, ihracat potansiyeli yüksek olan önemli sektörlerden birisidir (TUIK, 2016). Hollanda'daki kesme çiçek satı̧̧ değerleri incelendiğinde gül ve krizantem önemli bir paya sahiptir (Şirin, 2010). Bununla beraber lale ve zambak gibi soğanlı bitkilerde kesme çiçek sektöründe yoğun olarak yer almaya başlamıştır. Gösterişli ve vazo ömrü uzun olan çiçeklerinin tüketici tarafından tercih edilmesi, yıl boyu yetiştiriciliğe olanak sağlaması nedeni ile kesme çiçek olarak kullanılan Lilium sp.'nin üretim alanlarında ve ihracatında tüm dünyada olduğu gibi ülkemizde de artış yaşanmaktadır. Liliaceae familyasının önemli bir türü olan Lilium sp. çok yıllık soğanlı bir bitkidir. Soğanlı bitkilerde olduğu gibi lilyumların üretiminde de soğan pulları, koltuk altı soğanları, bölme yöntemi ve çiçek sapları gibi vejetatif üretim materyalleri kullanılmaktadır. Fakat oluşan yavru soğanların çiçek oluşturacak iriliğe ulaşması için yaklaşık 3 yıllık bir süreye ihtiyaç duyulmakta, bu durum işgücü kullanımını ve üretim maliyetlerini artırmaktadır (Korkut, 2004). Hollanda, dünya çiçek soğanı üretim alanlarının \% 70 'ini karşılayan en önemli çiçek soğanı üreticisi ve ihracatçısıdır (Karagüzel ve ark., 2007). Hollanda' nın yanı sıra başta İngiltere, Fransa olmak üzere 15 ülkede çiçek soğanı üretimi yapılmaktadır (Buschman, 2004; Karagüzel ve ark., 2007). Ülkemizde çiçek soğanlarının kültürü ile ilgili bilimsel ve ticari anlamda yürütülen çalışmalar ise henüz yenidir. Üretim materyalinde dışa bağımlılı̆̆ı azaltmak için soğan üretimi ve soğanların hızlı gelişimi konularına önem verilmesi gerekmektedir.

Kesme çiçek olarak yetiştirilen lilyumlar genelde kumlu-tınlı, geçirgen ve organik maddece zengin topraklarda yetiştirilmekle beraber, son yıllarda topraksız kültürde yetiştiriciliği de yapılmaktadır. Topraklı yetiştiricilikte Rhizoctonia solani, Phytophthora ssp., Fusarium spp., Verticillium spp., Pythium spp., Botrytis sp. gibi toprak kaynaklı hastalık etmenleri başarısızlıklara neden olmaktadır (Miller, 1998; Chase, 2005; Gümrükçü ve Gölükçü 2005; Şirin, 2011). Ancak seralarda yapılan yetiştiricilikte toprakların fiziksel ve kimyasal yapılarının uygun olmaması, monokültür uygulamalar, bilinçsiz gübrelemeler, kimyasal madde kullanımı ve tuzluluğun artması gibi nedenlerle toprak yorgunlukları yaşanması kesme çiçek verim ve kalitesini etkilediği gibi aynı zamanda üretim materyali olan yavru soğan oluşum miktarını ve kalitesini etkilemektedir. Ayrıca üretimde toprak kaynaklı sorunların yaşanması bakım ve işçilik maliyetlerinin artmasına neden olmaktadır. Toprak kaynaklı sorunların ç̧özümü için dezenfeksiyon, solarizasyon, yıkama gibi bir takım kültürel, fiziksel ve kimyasal yöntemler kullanılabilmektedir. Ancak bu yöntemlerden maliyet yüksekliği, işgücü kullanımını artırması veya kullanılan yöntemin üretim programı ile uyuşmaması gibi nedenlerle etkin bir şekilde yararlanılamamaktadır. $\mathrm{Bu}$ nedenle en kullanılabilir yöntem olarak topraksız kültürün ülkemizde de uygulanabilirliği en yüksek olan ortam (substrat) kültürü karşımıza çıkmaktadır (Tüzel ve Gül, 1999). Bu yetiştiricilikte torf, hindistan cevizi lifleri, talaş, ağaç kabuğu, çeltik kavuzu, yer fistığı kabuğu gibi organik ortamlar; kum, çakıl, volkan tüfü, perlit, vermikülit, genleştirilmiş kil, kaya yünü gibi inorganik ortamlar veya poliüretan köpük gibi sentetik ortamlar bulunmaktadır. Yetiştirme ortamlarının amacı, bitkiye destek olmak, bitkiyi daha az gübre ve su ile daha iyi bir şekilde besleyerek verim ve kalite artışını sağlamaktır. Fakat kullanılan yetiştirme ortamlarının bitki tür ve çeşitlerine, kimyasal ve fiziksel özelliklerine göre etkileri değişkenlik gösterebilmektedir (Maloupa ve ark., 1999; Klasman ve ark., 2002; Grassotti ve ark., 2003; Tribulato ve ark., 2003; Treder, 2008; Nikrazm ve ark., 2011). Bu nedenle topraksız tarımında en önemli faktörlerden biri bitki için en uygun yetiştirme ortamının seçilmesidir.

Lilyum ile ilgili yapılmış çalışmalara bakıldığında yetiştirme ortamı olarak hindistan cevizi kabuğu, vermikülit, çakıl, kum, volkanik curuf, torf, perlit, pirinç kavuzları tek başına veya karışımlar halinde kullanılmış olup çoğunlukla bitki verim ve kalite parametreleri incelenmiştir (Klasman ve ark., 2002; Grassotti ve ark., 2003; Tribulato ve ark., 2003; Tehranifar ve ark., 2010; Nikrazm ve ark., 2011; Bhandari ve Srivastava 2016). Genel olarak değerlendirildiğinde su tutma kapasitesi ve katyon değişim kapasitesi yüksek, düşük hacim ağırlığına, iyi fiziksel özelliklere ve gözenekli yapıya sahip hindistan cevizinin tek başına veya karışım halinde kullanımı bitki gelişimi ve çiçeklenmeyi olumlu yönde etkilediği belirlenmiştir (Seyedi ve ark., 2012; Bhandari ve Srivastava, 2016). Soğan gelişimi üzerine yapılan bir çalışmada da benzer şekilde hindistan cevizinde yetiştirilen toros kardeleninde en yüksek yavru soğan oranı $(\% 43,8)$ ve bitki boyu $(22,7 \mathrm{~cm})$ elde edilmiştir (Kahraman, 2015). Lilyumda yapılmış bir başka çalışmada ise ana soğan ve yavru soğan sayısı açısından en iyi değerlerin toprak- pirinç kavuzu karışımı ile nehir kumu- perlit karışımından elde edildiği belirtilmiştir (Klasman ve ark., 2002). Fakat ülkemizde kullanılan hindistan cevizi yurt dışından ithal edilmekte olup fiyatları oldukça pahalı olmaktadır. $\mathrm{Bu}$ sebeple ithal edilen yetiştirme ortamlarına alternatif ülkemizde kolay temin edilebilen, yüksek kalitede ve ekonomik yetiştiriciliğe olanak sağlayan yeni ortamların belirlenmesi önem taşımaktadır. Özellikle oluşan yavru soğanların kısa sürede büyütülerek çiçek verecek boyutlara ulaştırılması aşamasında ekolojik faktörler ve bitki beslemenin yanı sıra uygun yetiştirme ortamı seçimi de büyük önem taşımaktadır. Bu bağlamda süs bitkileri yetiştiriciliğinde, türe hatta çeşide özgü, ucuz, kolay bulunabilen ve bölgenin yerel kaynaklarından temin edilebilen yetiştirme ortamları ile ilgili çalışmalar önem kazanmaktadır. 
$\mathrm{Bu}$ çalışmada; farklı yetiştirme ortamlarında lilyum yetiştiriciliğinde soğan ile yavru soğan oluşumu ve gelişim üzerine olan etkilerinin incelenmesi amaçlanmıştır.

\section{Materyal ve Yöntem}

$\mathrm{Bu}$ çalışma 2011 yılı Şubat ve Haziran ayları arasında Adnan Menderes Üniversitesi Ziraat Fakültesinde Bahçe Bitkileri Bölümüne ait 1sıtmasız plastik örtülü serada yürütülmüştür. Bitkisel materyal olarak Lilium LA hybrids "Ceb Dazzle" çeşidi kullanılmıştır. Soğanlar Hollanda'dan ithalat yapan özel bir firmadan kasalar içerisindeki nemli torf içerisinde muhafazalı olarak temin edilmiş ve dikim zamanı kadar $4-5{ }^{\circ} \mathrm{C}$ sıcaklıkta muhafaza edilmiştir. Farklı yetiştirme ortamlarının yavru soğan oluşumu üzerine etkisinin incelendiği bu çalışmada; perlit, torf, kum, volkanik curuf, yerfistığı kabuğu, kestane kabuğu, hindistan cevizi kabuğu, toprak, ağır gübresi olmak üzere farklı materyaller tek başlarına veya hacimsel olarak karışımlar halinde kullanılmıştır. Çalışmada kullanılan materyallerle araştırmada yer alan 9 farklı yetiştirme ortamı oluşturulmuştur ve bu ortamlara iliş̧kin oranlar Çizelge 1'de verilmiştir.

Çizelge 1. Denemede kullanılan materyallerle oluşturulmuş yetiştirme ortamları

\begin{tabular}{ll}
\hline Ortam içeriği ve oranları & Oran \\
\hline Kestane kabuğu + Perlit (1:1) & $\% 50+\% 50$ \\
Yerfistığı kabuğu + Perlit (1:1) & $\% 50+\% 50$ \\
Yerfistığı kabuğu+ Kum (1:1) & $\% 50+\% 50$ \\
Perlit & $\% 100$ \\
Kestane kabuğu + Kum (1:1) & $\% 50+\% 50$ \\
Kontrol (Toprak+Ahırgübresi+Torf) (1:1:1) & $\% 33+\% 33+\% 33$ \\
Torf + Kum (1:1) & $\% 50+\% 50$ \\
Hindistan cevizi kabuğu & $\% 100$ \\
Volkanik Curuf & $\% 100$ \\
\hline
\end{tabular}

Lilyum bitkilerinin yetiştiriciliğinde yetiştirme yeri olarak 520x365×310 mm ebatlarında ve 60 litre hacimli alttan ve yandan geçirimli, siyah plastik kasalar kullanılmıștır. Kasaların dikime hazırlanması aşamasında öncelikli olarak içleri siyah plastik örtü ile kaplanmış ve tam ortalarından drenaj delikleri açılarak üzerine bir miktar çakıl taşı yerleştirilmiştir. Hazırlanan yetiştirme ortamları kasalara doldurulmuş ve kasalar deneme desenine göre seraya yerleştirilmiştir. Lilyum soğanlarının çapları ölçülerek birbirine yakın çapa sahip soğanlar denemede kullanılmıştır. Soğanlar kasalar içerisindeki yetiştirme ortamlarına $15 \times 15$ sıra arası ve üzeri mesafelerde, $10 \mathrm{~cm}$ derinliğe 28.02.2011 tarihinde dikilmiştir. Kasalar arasında sıra arası olarak $50 \mathrm{~cm}$ mesafe bırakılmıştır.

Bitkilerin sulanması ve beslenmesi kasalar üzerinden geçirilen lateral damla sulama boruları ile gerçekleştirilmiştir. Dikimden sonra soğanların uyanması ve sürgün oluşturması gözlenmiş ve bitki boyu $10-15 \mathrm{~cm}$ olana kadar sadece sulama suyu verilmiştir. Daha sonra bitkiler besin solüsyonu ile beslenmeye başlamış ve besleme ile sulama birlikte yapılmıştır. Bitkilerin beslenmesinde; 160 ppm N, 46.3 ppm P, 224.3 ppm K, 18.2 ppm Mg, 140 ppm Ca, 1.95 ppm Fe, 0.41 ppm Mn, 0.21 ppm B, 0.03 ppm Cu, 0.19 ppm Zn ve 0.04 ppm Mo içeren "Schwarz" besin solüsyonu (Schwarz, 1995) kullanılmıştır. Besin solüsyonu uygulama süresi ve sıklı̆̆ı, ekolojik koşullara bağlı olarak değişkenlik göstermiş fakat tüm uygulamalarda aynı olarak gerçekleştirilmiştir. Solüsyonunun uygulanma miktarı ise uygulanan besin solüsyonun \%20-30'u drene olacak kadar yapılmıștır (Özzambak ve Zeybekoğlu, 2004).

Araştırma tesadüf blokları deneme desenine göre 3 tekerrürlü olarak düzenlenmiştir. Her tekerrürde 20 adet lilyum soğanı olmak üzere her uygulamada 60 adet soğan yer almış olup, toplamda denemede 540 adet soğan dikilmiştir. Araştırmada kullanılan 9 farklı yetiştirme ortamının bitki gelişimi, soğan ve yavru soğan gelişimi üzerine etkilerini belirlemek amacı ile incelemeler yapılmıştır. Bu amaçla; çiçek dalı uzunluğu $(\mathrm{cm})$, çiçek dalı yaş ağırlığ $1(\mathrm{~g})$, ana soğan üzerindeki kök sayısı (adet), uzunluğu (cm), yaş ve kuru ağırlığı (g) ile gövde üzerinde oluşan köklerin yaş ve kuru ağırlığına (g) ait değerleri belirlenmiştir. Denemede dikilen ana soğanlar üzerinde yavru soğan oluşmadığı için herhangi bir inceleme yapılamamıştır. Gövde üzerinde oluşan yavru soğanlarda ise sayı, ağırlık, en ve boy değerleri ile şekil indeksi (en/boy oranı) saptanmıştır. Elde edilen verilere TARIST istatistiksel analiz programında varyans analizi yapılmıştır. Ortalamaların karşılaştırılıp farklılıkların ortaya konması içinde $\% 5$ hata olasıllığına sahip LSD testi kullanılmıştır. Elde edilen sonuçlar ile ortalamalar gruplandırılmıştır. 


\section{Bulgular ve Tartışma}

\subsection{Ana Soğan Gelişimi}

Farklı yetiştirme ortamların bitki gelişimi ve soğan gelişimi üzerine etkisini araştırmak amacıyla yürütülen denemede bitki gelişimine ilişkin çiçek dalı uzunluğu ve yaş ağırlık değerleri belirlenmiştir (Çizelge 2).

Denemede kullanılan ortamların, çiçek dalı uzunluğu ve çiçek dalı yaş ağırlığı değerleri üzerine istatistiksel olarak önemli etkisinin olduğu saptanmıştır. Çiçek dalı uzunluk değerleri $69.67 \mathrm{~cm}$ ile $92.40 \mathrm{~cm}$ arasında belirlenmiştir. En uzun çiçek dalı perlit ortamında yapılan yetiştiricilikten $92.40 \mathrm{~cm}$ ile elde edilirken, en kısa çiçek dalı ise $69.67 \mathrm{~cm}$ ile kestane+perlit ortamında yetiştirilen bitkilerden elde edildiği saptanmıştır. Maloupa ve Gerasopoulos (1997) 'da çalışmalarında en yüksek verimi perlit ortamında gerçekleştirdikleri yetiştiricilikten elde ettiklerini bildirmişlerdir. Minuto ve Accati (1995) tarafindan da benzer sonuçlar elde edilmiştir. Bitki gelişimi açısından diğer bir önemli kriter olan çiçek dalı yaş ağırlık değerleri ise $71.837 \mathrm{~g}$ ile $143.963 \mathrm{~g}$ arasında değişmiş olup en yüksek değerler yerfıstığ 1 kabuğu + perlit ortamından elde edilirken en düşük değerler ise kestane kabuğu + perlit ortamında belirlenmiştir. Farklı gerbera çeşitlerinde de çiçek dalı yaş ağırlıklarının ortam kültüründe, topraklı kültürden daha iyi sonuç verdiği saptanmıştır (Hahn ve ark., 2001).

Ana soğan gelişimlerini incelemek amacıyla; deneme sonunda sökülen soğanlarda yavru oluşumu ve oluşan yeni soğanların ağırlık en ve boy değerleri üzerine istatiksel analiz yapılmış ve genel olarak değerlendirildiğinde yetiştirme ortamlarının ana soğanda yavru oluşumu üzerine istatistiki olarak önemli etkilerinin olmadığı ve tüm uygulamalarda 1 adet soğan bulunduğu görülmüştür. Ana soğanda oluşan yeni soğanın ağırlığı ve eni yetiştirme ortamlarına göre değişim göstermemiş, yeni oluşan bu soğanların eni ise yetiştirme ortamlarına bağlı olarak $17.58 \mathrm{~mm}$ ile 25.66 $\mathrm{mm}$ arasında değişmiştir (Çizelge 3). Oluşan soğanların boy değerleri incelendiğinde en yüksek boya sahip soğanlar $26.43 \mathrm{~mm}$ ile kestane kabuğu + perlit ortamında elde edilmiştir. Bu anlamda ortamların yavru soğan boyu üzerine \%99 güvenle istatistiki olarak önemli etkisinin olduğu görülmektedir.

Çalışmada ayrıca sökülen soğanlarda ve bitki gövdesi (kök boğazı) üzerinde oluşan kökler üzerine yetiştirme ortamlarının etkisi incelenmiştir. Ana soğan ve gövde üzerinde oluşan köklerin kuru ağırlıkları hariç ana soğan üzerinde oluşan kök sayısı, kök uzunluğu, kök yaş ağırlığı ile gövde üzerinde oluşan köklerin yaş ağırlığı üzerine yetiştirme ortamlarının önemli etkisi olduğu belirlenmiştir. (Çizelge 4).

Çizelge 4'den görüldüğü üzere; yetiştirilen lilyum bitkilerinin vegetasyon dönemi sonunda sökülen ana soğanları üzerinde belirlenen kök sayıları 4.50 ile 9.17 adet/soğan arasında değişim göstermiştir. En fazla kök kestane kabuğu+kum yetiştirme ortamında yetiştirilen soğanlarda saptanırken, en az kök yerfistığ $1+k u m$ yetiştirme ortamında yetiştirilen soğanlarda saptanmıştır. Kök uzunlukları açısından ise en uzun kökler kestane kabuğu+perlit'de yetiştirilen soğanlarda saptanmış bunu $29.82 \mathrm{~cm}$ ile kestane kabuğu+kum izlemiştir. Kardelen bitkisinde yapılan bir çalışmada, en yüksek kök uzunluğu değerlerinin hindistan cevizi ve torf+ perlit karışımında elde edildiği belirlenmiştir (Yıldırım ve ark., 2015). Kök sayıları açısından da denemede kullanılan birçok yetiştirme ortamına göre daha düşük bir performans gösteren volkanik curuf ortamında yetiştirilen soğanlarda en kısa köklerin oluştuğu saptanmıştır.

Çizelge 2. Denemede kullanılan yetiştirme ortamlarının bitki gelişimi üzerine etkisi

\begin{tabular}{lcc}
\hline Yetiştirme Ortamları & Çiçek Dalı Uzunluğu $(\mathrm{cm})$ & Çiçek Dalı Yaş Ağırlığı $(\mathrm{g})$ \\
\hline Kestane Kabuğu + Perlit & $69.67 \mathrm{e}$ & $71.837 \mathrm{f}$ \\
Yerfistığı kabuğu + Perlit & $88.41 \mathrm{ab}$ & $143.963 \mathrm{a}$ \\
Yerfıstığı kabuğu+ Kum & $92.38 \mathrm{a}$ & $131.113 \mathrm{~b}$ \\
Perlit & $92.40 \mathrm{a}$ & $121.010 \mathrm{bc}$ \\
Kestane kabuğu + Kum & $87.41 \mathrm{~b}$ & $109.580 \mathrm{~d}$ \\
Kontrol & $84.52 \mathrm{bc}$ & $118.757 \mathrm{~cd}$ \\
Torf + Kum & $82.51 \mathrm{~cd}$ & $120.777 \mathrm{bc}$ \\
Hindistan cevizi kabuğu & $79.78 \mathrm{~d}$ & $90.750 \mathrm{e}$ \\
Volkanik cüruf & $87.30 \mathrm{~b}$ & $117.350 \mathrm{~cd}$ \\
LSD\%5 & $21.172^{* *}$ & $36.485^{* *}$ \\
\hline
\end{tabular}


Çizelge 3. Denemede kullanılan farklı yetiştirme ortamların, ana soğanda gelişen yavru soğan sayıları, ağırlıkları, en ve boy değerleri üzerine etkisi

\begin{tabular}{lcccc}
\hline Yetiştirme Ortamları & $\begin{array}{c}\text { Yavru soğan } \\
\text { sayısı (adet) }\end{array}$ & $\begin{array}{c}\text { Yavru soğan ağırlı̆̆ } \\
(\mathrm{g})\end{array}$ & $\begin{array}{c}\text { Yavru Soğan } \\
\text { Boyu (mm) }\end{array}$ & $\begin{array}{c}\text { Yavru Soğan } \\
\text { Eni (mm) }\end{array}$ \\
\hline Kestane Kabuğu + Perlit & 1.00 & 4.500 & $26.43 \mathrm{a}$ & 21.59 \\
Yerfistığı kabuğu + Perlit & 1.00 & 3.510 & $22.96 \mathrm{c}$ & 20.30 \\
Yerfistığı kabuğu+ Kum & 1.00 & 3.577 & $24.98 \mathrm{ab}$ & 20.52 \\
Perlit & 1.00 & 4.057 & $23.37 \mathrm{bc}$ & 25.66 \\
Kestane kabuğu + Kum & 1.00 & 3.990 & $24.45 \mathrm{bc}$ & 20.62 \\
Kontrol & 1.00 & 3.597 & $20.32 \mathrm{~d}$ & 18.30 \\
Torf + Kum & 1.00 & 3.383 & $23.44 \mathrm{bc}$ & 19.21 \\
Hindistan cevizi kabuğu & 1.00 & 3.647 & $24.38 \mathrm{bc}$ & 19.33 \\
Volkanik curuf & 1.00 & 2.077 & $20.34 \mathrm{~d}$ & 17.58 \\
LSD \%5 & ö.d & ö.d & $11.069 * *$ & ö.d \\
\hline
\end{tabular}

öd: önemli değil $\quad *: p=0.05$ ' e göre önemli $\quad * *: p=0.01$ 'e göre önemli

Çizelge 4. Denemede kullanılan yetiştirme ortamlarının kök gelişimi üzerine etkisi

\begin{tabular}{|c|c|c|c|c|c|c|c|c|c|}
\hline \multirow[t]{2}{*}{ Yetiştirme Ortamları } & \multicolumn{6}{|c|}{ Ana Soğan Üzerindeki Kök } & \multicolumn{3}{|c|}{ Gövde Üzerindeki Kök } \\
\hline & $\begin{array}{l}\text { Say1s1 } \\
\text { (adet) }\end{array}$ & & Uzunluğu(cm) & Yaş Ağır & $\operatorname{lğ} 1(g)$ & $\begin{array}{l}\text { Kuru } \\
\text { Ağırlığı (g) }\end{array}$ & $\begin{array}{l}\text { Yaş } \\
\text { Ağırlığ1 }\end{array}$ & & $\begin{array}{l}\text { Kuru } \\
\text { Ağırlığ } \\
(\mathrm{g})\end{array}$ \\
\hline Kestane Kabuğu + Perlit & 7.83 & $a b$ & 33.78 a & 10.723 & $a b$ & 0.910 & 8.230 & $\mathrm{a}$ & 0.550 \\
\hline Yerfıstığ 1 kabuğu+Perlit & 6.17 & $\mathrm{bc}$ & $22.63 \mathrm{bcd}$ & 4.610 & de & 0.453 & 4.693 & $\mathrm{~b}$ & 0.420 \\
\hline Yerfistığı kabuğu+ Kum & 4.50 & $\mathrm{c}$ & $20.15 \mathrm{~cd}$ & 3.787 & $\mathrm{e}$ & 0.900 & 4.687 & b & 0.675 \\
\hline Perlit & 8.00 & $a b$ & $23.18 \mathrm{bcd}$ & 9.430 & b & 0.547 & 8.433 & a & 0.500 \\
\hline Kestane kabuğu + Kum & 9.17 & $\mathrm{a}$ & $29.82 \mathrm{ab}$ & 11.037 & $\mathrm{a}$ & 0.640 & 7.607 & $\mathrm{a}$ & 0.655 \\
\hline Kontrol & 5.00 & $\mathrm{c}$ & $24.52 \mathrm{bcd}$ & 3.590 & $\mathrm{e}$ & 0.000 & 2.207 & $\mathrm{c}$ & 0.515 \\
\hline Torf + Kum & 6.17 & $\mathrm{bc}$ & $26.80 \mathrm{abc}$ & 5.440 & $\mathrm{~d}$ & 0.993 & 3.823 & $\mathrm{bc}$ & 0.937 \\
\hline Hindistan cevizi kabuğu & 6.83 & $a b c$ & $26.32 \mathrm{abc}$ & 10.000 & $a b$ & 0.600 & 8.833 & $\mathrm{a}$ & 1.530 \\
\hline Volkanik curuf & 5.50 & bc & $15.73 \mathrm{~d}$ & 7.007 & $\mathrm{c}$ & 1.950 & 5.227 & b & 0.720 \\
\hline LSD $\% 5$ & $2.730 *$ & & $3.201 *$ & $35.955^{* *}$ & & ö.d & $15.784 * *$ & & ö.d. \\
\hline
\end{tabular}
öd: önemli değil $\quad *: \mathrm{p}=0.05$ ' e göre önemli $\quad * *: \mathrm{p}=0.01$ 'e göre önemli

Ana soğanlarda belirlenen soğan kök yaş ağırlıklarının ise yetiştirme ortamına bağlı olarak 3.590 gile11.037 g arasında değiştiği belirlenmiştir (Çizelge 4). En yüksek soğan kök yaş ağırlığı kestane kabuğu+kum ortamında belirlenmiş, bunu $10.723 \mathrm{~g}$ ile kestane kabuğu+perlit izlemiştir. Soğan kök kuru ağırlıkları ise $0.453 \mathrm{~g}$ ile $1.950 \mathrm{~g}$ arasında değişmiştir.

Gövde üzerinde gelişen köklere ilişkin en yüksek yaş ağırlık değeri ise $8.833 \mathrm{~g}$ ile hindistan cevizi kabuğunda belirlenmiş, bunu $8.433 \mathrm{~g}$ ile perlit ve 8.230 g ile kestane kabuğu + perlit yetiştirme ortamı izlemiştir. Çalışmadan elde edilen sonuçlar genel olarak değerlendirildiğinde, farklı yetiştirme ortamlarının kök gelişimi üzerine farklı etkileri olduğu ifade edilebilir.
Nitekim Treder (2008)' de yaptığ sistemlerinin yetiştirme ortamı olarak hindistan cevizi kabuğu kullanılan, lilyum yetiştiriciliğinde daha iyi gelişism gösterdiğini saptamıştır.

Gövde ve ana soğan üzerinde gelişen köklerin kuru ağırlıklarına bakıldığında ise belirlenen farklılıklar istatistiksel olarak önemli bulunmamıştır (Çizelge 4).

\subsection{Yavru Soğan Gelişimi}

Farklı yetiştirme ortamlarının yavru soğan gelişimine etkisini belirlemek amaciyla sökülen lilyumlarda; gövde üzerinde gelişen yavru soğanların sayısı, ağırlığı, en ve boy değerleri saptanmıştır (Çizelge $5)$. 
Çizelge 5. Denemede kullanılan yetiştirme ortamlarının gövde üzerinde oluşan yavru soğanların gelişimi üzerine etkisi

\begin{tabular}{|c|c|c|c|c|c|c|c|}
\hline Yetiştirme Ortamları & $\begin{array}{l}\text { Yavru Soğan } \\
\text { Sayısı(adet) }\end{array}$ & $\begin{array}{l}\text { Yavru Soğan } \\
\text { Ağırlığı(g) }\end{array}$ & \multicolumn{2}{|c|}{$\begin{array}{c}\text { Yavru Soğan } \\
\text { Boyu(mm) }\end{array}$} & \multicolumn{2}{|c|}{$\begin{array}{c}\text { Yavru Soğan } \\
\text { Eni }(\mathrm{mm})\end{array}$} & $\begin{array}{l}\text { Soğan şekil } \\
\text { indeksi }\end{array}$ \\
\hline Kestane Kabuğu + Perlit & 9.50 & 3.593 & 13.07 & $\mathrm{bc}$ & 11.35 & $\mathrm{~cd}$ & 0.86 \\
\hline Yerfistığı kabuğu + Perlit & 8.33 & 4.493 & 13.98 & $a b$ & 12.65 & $a b c$ & 0.90 \\
\hline Yerfistığ1 kabuğu+ Kum & 17.50 & 12.387 & 14.54 & $\mathrm{a}$ & 14.34 & $\mathrm{a}$ & 0.98 \\
\hline Perlit & 14.00 & 6.283 & 12.48 & $\mathrm{c}$ & 11.50 & $\mathrm{~cd}$ & 0.92 \\
\hline Kestane kabuğu + Kum & 7.67 & 4.787 & 13.31 & $\mathrm{bc}$ & 12.83 & $a b c$ & 0.96 \\
\hline Kontrol & 12.17 & 8.653 & 12.94 & $\mathrm{bc}$ & 12.76 & $a b c$ & 0.98 \\
\hline Torf + Kum & 15.67 & 8.983 & 14.42 & $\mathrm{a}$ & 13.31 & $a b$ & 0.92 \\
\hline Hindistan cevizi kabuğu & 12.00 & 6.303 & 13.50 & $a b c$ & 12.34 & $\mathrm{bc}$ & 0.91 \\
\hline Volkanik curuf & 8.50 & 2.907 & 10.90 & $\mathrm{~d}$ & 10.11 & $\mathrm{~d}$ & 0.92 \\
\hline LSD $\% 5$ & ö.d & ö.d. & & & 4.398 & & \\
\hline
\end{tabular}

öd: önemli değil

Çizelge 5 incelendiğinde gövde üzerinde oluşan yavru soğan sayısı ve yavru soğan ağırlı̆̆ üzerine yetiştirme ortamlarının istatistiksel olarak önemli bir etkisinin olmadığ 1 belirlenmiştir. Benzer şekilde Kahraman (2015), kardelende yürüttüğü çalışmada, yavru soğan oluşumu oranı üzerine kullanılan ortamların istatistiksel bir etkisinin olmadığını belirlemiştir. Gövde üzerinde gelişen yavru soğanların en ve boyları incelendiğinde, farklı yetiştirme ortamında oluşan yavru soğanların en ve boyları arasında farklılıklar olduğu saptanmıştır. Yavru soğanların boyları $10.90 \mathrm{~mm}$ ile $14.54 \mathrm{~mm}$ arasında değişmekte ve yavru soğan boy değeri en büyük olan yavru soğanların yer fistığı kabuğu+kum' da, en küçük olanlar ise volkanik curuf'dan elde edilmiştir. Gövde üzerinde oluşan yavru soğanların en değerleri ise en yüksek $14.34 \mathrm{~mm}$ ile yerfistığ edilirken bunu $13.31 \mathrm{~mm}$ ile torf + kum izlemiştir. Yavru soğan eni açısından $10.11 \mathrm{~mm}$ ile en düşük değer, volkanik cüruf ortamından saptanmıştır(Çizelge $5)$.

Çizelge 5'te verilen soğan şekil indeksi (en/boy oranı) incelendiğinde, indeks değerleri 1 ile 0.75 arasında değișen yavru soğanların oval olduğu saptanmıştır (Lippert ve Legg, 1972; Koca, 2013).

Lilyum'da bitki gelişimi ve yavru soğan sayısına ilişkin korelasyon katsayılarına ait tablo Çizelge 6'da verilmiştir.

Çizelge 6. Yavru soğan sayısı ile bitki gelişim özellikleri arasındaki ilişkiler

\begin{tabular}{llll}
\hline & Çiçek Dalı Uzunluğu & Çiçek Dalı Yaş Ağırlı̆̆ & Yavru SoğanSayısı \\
\hline Çiçek Dalı Uzunluğu & 1 & $0.848^{* *}$ & 0.270 \\
Çiçek Dalı Yaş Ağırlığı & $0.848^{* *}$ & 1 & 0.228 \\
Yavru SoğanSayısı & 0.270 & 0.228 & 1 \\
\hline
\end{tabular}

öd: önemli değil * $\quad$ p $=0.05$ ' e göre önemli

Gelişim ve yavru soğan sayısı ile çiçek dalı uzunluğu, çiçek dalı yaş ağırlığı arasındaki ilişkiler incelendiğinde; yavru soğan sayısının çiçek dalı uzunluğu ve yaş ağırlığıyla önemli ilişkisi olmadığı saptanmıştır. Çiçek dalı uzunluğu ile çiçek dalı yaş ağırlığı arasındaki ilişki ise önemli bulunmuştur. Ana soğan üzerinde gelişen yavru soğan sayıları incelendiğinde herhangi bir farklılık göstermemiş ve tüm yetiştirme ortamlarında 1 adet yavru soğan elde edilmiştir. Bu sebeple çalışmada dikkate alınmamıştır.

\section{Sonuç}

Soğan gelişimlerini belirlemek amacıyla yapılan ölçümlerden elde edilen değerlere bakıldığında, ana
**: $\mathrm{p}=0.01$ 'e göre önemli

soğan üzerindeki kök sayısı ve yaş ağırlıklarına ait değerlerin en yüksek kestane kabuğu+kum yetiştirme ortamında olduğu belirlenmiştir. Soğan gelişimi açısından önemli olan soğan kök uzunluğunda en yüksek değerler kestane+perlit ortamında yetiştirilen bitkilerden elde edilmiştir. Gövde üzerindeki köklerin yaş ağırlığı ise en yüksek perlit yetiştirme ortamında belirlenirken ve kuru ağırlık değeri istatistiki açıdan önemsiz bulunmuştur.

Yavru soğan gelişimleri incelendiğinde en yüksek yavru soğan sayısı, yavru soğan boy, yavru soğan en ve yavru soğan ağırlık değerleri yer fisttğ 1 kabuğu+kum karışımından oluşan yetiştirme ortamından elde edilmiştir. 
Yavru soğan sayısı ile bitki gelişimi arasındaki ilişki incelendiğinde yavru soğan sayısının, çiçek dalı uzunluğu ve çiçek dalı yaş ağırlığı ile ilişkisinin olmadığı fakat çiçek dalı uzunluğu ile çiçek dalı yaş ağırlığı arasındaki ilişkinin önemli olup çiçek dalı uzunluğu arttıkça çiçek dalı yaş ağırlığında artış gösterdiği belirlenmiştir.

\section{Kaynaklar}

Bhandari N.S., Srivastava R., 2016. Assessment of growing media on vegetative, flowering and vase life characteristics of Lilium (Lilium longiflorum) cvs. Bach and Pavia in the foothills of himalayas. Journal of Applied Biotechnology, ISSN 2327-0640 2016, Vol. 4, No.1.

Buschman J .C.M., 2004. Production of bulbs and bulb cut flowers in the world present and future. IXth International Symposium on FlowerBulbs, 19-22 April 2004.

Chase A.R., 2005. Rhizoctonia diseases on ornamentals. Leaders, Horticulture, 1(1): 1-4.

Gümrükçü, E., Gölükcü, Ş.B., 2005. Süs bitkilerinde görülen fungal ve bakteriyel hastalıklar. Derim-Batı Akdeniz Agric. Res. Inst. ISSN 1300 3496, 22 (2):10-19, Antalya.

Grassotti, A., Nesi, B., Maletta, M., Magnani, G., 2003. Effects of growing media and planting time on lily hybrids in soillessculture. Acta Horticulturae, 609: 395-399.

Hahn, E., Jeon, N., Paek, K., 2001. Culture method and growing medium affect growth and flower quality of several gerbera cultivars. Acta Horticulturae, 548: 385-391.

Kahraman, Ö., 2015. Farklı yetiştirme ortamlarının toros kardeleni (Galanthus elwesii Hook.)'nin soğan performansı üzerine etkileri. ÇOMÜ Zir. Fak. Derg. (COMU J. Agric. Fac.) 3(1): 109-114.

Karagüzel, Ö., Aydınşakir, K., Kaya, A.S., 2007. Dünyada ve Türkiye'de çiçek soğanları sektörünün durumu. Batı Akdeniz Tarımsal Araştırma Enstitüsü, Antalya.

Klasman, R., Moreira, D., Benedetto, A., 2002. Cultivation of asiatichybrids of lilium sp. in three different substrates. Catedra de Floricultura, Facultad de Agronomia (U.B.A.), Volume: 22, Issue: 1, pp. 79-83. Av. San Martin 4453 (1417), Buenos Aires, Argentina.

Koca, N., 2013. Bazı organik gübrelerin tohumdan baş soğan (Allium cepa L.) üretiminde verim ve kaliteye etkileri. Selçuk Üniversitesi, Fen Bilimleri Enstitüsü, Yüksek Lisans Tezi, Konya.

Lippert, L.F., Legg, P.D., 1972. Appearance and quality characters in musk melon fruit valved by a ten cultivars dralled cross. J. Am. Soc. Hort. Sci. 97(1): 84-87

Maloupa, E., Khelifi, S., Zervaki, D., 1999. Effect of growing media on the production and quality of two rose varieties. ISHS Acta Horticulturae 548: International Symposium on Growing Media and Hydroponics.

DOI: 10.17660/ActaHortic.2001.548.7

Maloupa, E., Gerasopoulos, D., 1997. Quality production of four cut gerberas in a hydroponic system of four substrates. ISHS Symposium on Greenhouse Management for Better Yield and Quality in Mild Climates, Antalya 3-5 Nov.,1997.

Miller, R.O., 1998. Lilium (in Ball Red Book, ed. by V. Ball), 16th edition. 335 North River Street, Batavia, Illinois, 60510, USA.

Minuto, G., Accati, E., 1995. Cut flower carnations, cultivation on perlit. Culture- protette, 24:113-116.

Nikrazm, R., Ajirlou, A.S., Khaligy, A., Tabatabaei, S.J., 2011. Effects of different media on vegetative growth of two Lilium cultivars in soilless culture. J. Sci. \&Technol. Green house Culture, Vol. 2, No. 6, Isfahan Univ. Technol.,Isf., Iran.

Özzambak, E., Zeybekoğlu, E., 2004. Serada topraksız gerbera yetiştiriciliği ve bazı yetiştirme ortamlarının karşılaştırılması. İzmir Ticaret Odası Yayın No:140, İzmir.

Schwarz, M., 1995. Soilless culture management. Advanced Series in Agricultural Sciences 24, Jerusalem, Israel.

Seyedi, N., Mohammadi Torkashv, A., Allahyari, M.S., 2012. The Impact of perlite and cocopeat as the growth media on lilium. Asian Journal of Experimental 3(3): 502-505.

Şirin, U., 2010. Süs bitkileri yetiştiriciliği ders notları. Adnan Menderes Üniversitesi, Ziraat Fakültesi, Bahçe Bitkileri Bölümü. Aydın.

Şirin, U., 2011. Determining the effects of Trichoderma harzianum and some mycorrhizal fungi on plant growth and against Rhizoctania solani Kühn in Lilium under in vivo conditions. African Journal of Biotechnology, 10(67): 15142-15150.

Treder, J., 2008. The effects of cocopet and fertilization on the groth and flowering of oriental lily 'Star Gazer'. Journal of Fruit and Ornamental Plant Research, 16: 361-370.

Tribulato, A., Noto, G., Argento, S., 2003. Soilless culture on quality production in lily. Dipartiment odi Orto Floro Arbori coltura e Tecnologie Agroalimentari (DOFATA), University of Catania, ViaValdisavoia, 5 - 95123 Catania, Italy. Acta Horticulturae, 2 (614): 749-754.

TUIK, 2016. Türkiye İstatistik Kurumu Verileri. http://www.tuik.gov.tr/PreTablo.do?alt_id=1001 Erişim tarihi: 21.11.2016.

Yıldırım, M., Kahraman, Ö., Akçal, A., 2015. Farklı yetiştirme ortamları ve kısıtlı su uygulamalarının kardelen soğan gelişimi üzerine etkileri. Bahçe özel say1; VII Bahçe Bitkileri Kongresi Bildirileri- Cilt II: Sebzecilik Bağcılık- Süs Bitkileri 